International Journal of Linguistics, Literature and Culture
Available online at https://sloap.org/journals/index.php/ijllc/
Vol. 5, No. 3, May 2019, pages: 71 80
$\begin{aligned} & \text { ISSN: 2455-8028 } \\ & \text { https://doi.org/10.21744/ijllc.v5n3.659 }\end{aligned}$

\title{
Commercial Automotive Advertising: Semiotic Study
}

Gusti Ngurah Aditya Krisnawan ${ }^{\text {a }}$ Ni Luh Sutjiati Beratha ${ }^{\text {b }}$ I Ketut Darma Laksana $^{c}$

\section{Article history:}

Received: 27 January 2019

Accepted: 31 March 2019

Published: 31 May 2019

\section{Keywords:}

automotive advertisement; icon;

index; semiotic; symbol;

\begin{abstract}
Automotive commercial advertising is an advertisement that is often aired on television. As one of the countries with the largest automotive vehicle consumers in Asia, many advertisements are issued by motor vehicle manufacturers so that the products they offer are purchased by the public. This paper will discuss how the existing advertisement structure displays signs that are effective and efficient so that with a short duration, an advertisement can provide a lot of information. The problems discussed in this paper are what the role of the icon, index, and symbol in the automotive advertisements that are broadcasted on television. The data source in this paper uses advertisements data from Yamaha and Honda motorcycles. The research method in this paper uses the Peirce semiotic method that discusses the icon, index, and symbol in the advertisement. The method used in presenting the results of the analysis is formal and informal methods.
\end{abstract}

2455-8028 ${ }^{\circ}$ Copyright 2019. The Author. This is an open-access article under the CC BY-SA license (https://creativecommons.org/licenses/by-sa/4.0/) All rights reserved.

\section{Author correspondence: \\ Gusti Ngurah Aditya Krisnawan, STIKOM Bali \\ Jl. Raya Puputan Niti Mandala No.86, Renon, Kec. Denpasar Sel., Kota Denpasar, Bali 80221 \\ Email address: aditya300987@gmail.com}

\section{Introduction}

Advertising is a form of the marketing strategy for goods and services issued by a producer to attract the attention of consumers. The existence of advertisements in modern times is very easy to find. Apart from the enormous consumption power of the community, there is also industrial competition in providing strict products and services so that each producer wants to be superior and well-known from other producers. Cook (1992), states that advertising is a type of prominent discourse in all contemporary societies, and we live in a society where advertising has become a part of society or is rapidly developing. The most important thing that distinguishes discourse advertising from others is its function, namely to persuade people to buy a particular product. An attractive advertisement could determine

a STIKOM Bali, Denpasar, Indonesia

${ }^{\mathrm{b}}$ Udayana University, Denpasar, Indonesia

${ }^{\mathrm{c}}$ Udayana University, Denpasar, Indonesia 
whether the goods and services advertised would want to be bought by consumers. Therefore the producers begin to create advertisements that are interesting and easy to remember by people so that the competitiveness of the products offered can continue to survive.

In terms of psychology, the power of advertising depends on people's weaknesses, namely the unlimited human needs for solutions, suggestions, miraculous products, or objects that provide (or at least promise) a hope. Hope in this context refers to, for example, getting a better self-confidence or appearance, making a lot of money, gaining popularity or personal pride, better health, the security of health or from old age threats, comfort, erotic stimulation, emotional security and others (Beasley \& Danesi 2002). In other words, producers of goods and services target how to find the weaknesses of consumers so that they will buy goods and services they sell. The advertisements began to be created by focusing on product excellence that made the previous generation of products inferior, causing consumers who saw advertisements to feel the products they already had were outdated or worse than the new products. Shame in having something old or obsolete is the target of existing advertisements so that consumers want to buy the goods and services advertised. In other words, advertisers will always offer products or services that meet the needs or desires of consumers (Melchenko 2003).

Targeting human insecurity or sensitivity is the most frequently used strategy in making a successful advertisement (Goddard 2005). This includes the psychology of human beings who want to be the best and have the newest and most sophisticated things. This human nature is also used by advertising producers in marketing their advertisements. Many examples of advertisements in circulation claim that the products they offer are superior to what consumers already have. There are even those who offer products that make people feel proud of a brand that has a higher degree in the community if they have a product with a particular brand.

Levi (1959), states that the product is a 'sales symbol'. What is meant by this is that most products are bought and consumed based on their symbolic and pragmatic values? This statement explains how a product is bought by the community not only based on the functions it has but also based on a sense of satisfaction in having a product that represents a certain value.

According to Pinson (1998), products (and services) have three symbolic goals. First, the product gives consumers to create meaning to them, to symbolize who they are (self-concept theory). Second, the product is a very important sign in creating identity and status in the eyes of others. Third, the product is very important for the symbolic expansion of self. The above statement makes advertisements made by producers are very important because, with the right advertisements, they can change people's perceptions of their products, and the brands they sell. Advertising must have the right elements in offering their products, both with statements that support the superiority of their products, and what images should be displayed in order to be able to attract attention and the public can connect with the advertisements offered so that the desire to buy goods and services appears.

In Indonesia, the automotive market share is one of the best-selling market shares. The people's purchasing rate for automotive products is very high. This can be seen from the existence of many motorized vehicles in Indonesia which causes traffic jams in the big cities. This also depends on the desire of people to have a vehicle that can be used anytime and anywhere at any time, so that with the progress of time, it makes motor vehicles become more and more in demand and public transportation that used to be crowded is now becoming less and less desirable. This can be seen from a large number of public transports that began to disappear and were replaced by private vehicles that passed a lot on the streets.

High selling power also causes very strong competitiveness to emerge. With the wrong marketing strategy, not a few automotive companies are starting to dim, even bankrupt and out of competition in Indonesia. Companies such as Ford and Chevrolet are a series of automotive companies that have retreated from the automotive competition in Indonesia. Suzuki's motorcycle division also began to fade because of its very low sales. This can be seen from the number of Suzuki motorcycle dealers in Bali that was closed due to low sales. Therefore, the right product marketing is one of the keys to surviving in automotive competition in Indonesia.

The best-selling automotive product in Indonesia is a motorcycle. This can be seen from the number of motorcycle owners in Indonesia compared to other countries. With many motorcycle consumers in Indonesia, there are also many motorcycle advertisements in circulation. These advertisements display images that have certain meanings that support the text in the ad. The right images can be interpreted by consumers when watching advertisements on television. An image can be a sign that supports the statement in the ad. Signs included in an advertisement are very important so that consumers can interpret what is seen in the ad. Appropriate interpretation will make consumers feel interested in what they see; therefore the right sign that contains an interpretation that is easily understood by consumers is an important factor in an advertisement. This reason causes automotive advertisements to be very interesting objects to study. 
This research will use automotive advertisements as its data source, especially audio-visual advertisements. The signs contained in the advertisement will be examined using the semiotic theory. Semiotic is a branch of science that studies signs. The sign starts with the creation of a symbol of language in the form of sound by humans. The symbol of language in the form of sound, which then becomes a word, is a term that represents objects or objects that exist in this world. These words are referred to as sign, which in de Saussure's semiotics are referred to as signifier. The object symbolized by sound is called a signified. In advertisements, the signs are not only on the sound but also on the image displayed. According to Peirce, there is a process called semiosis which involves three elements, namely representamens, objects, and interpretants. The theory of Peirce is very suitable to be used to examine what objects exist in the advertisements that are considered to have representamens values that make consumers feel interested in what they see in automotive advertisements. Effective advertising not only has a dialogue that can convince readers to be interested in the products offered, but also must be smart in representing the right visuals to complement all existing dialogues so that it visually becomes an ad that can attract attention and be easily remembered.

\section{Materials and Methods}

This study uses 2 types of data, namely primary data and secondary data. The primary data in this study consisted of audio-visual advertisements that were aired on television. The type of advertisement used in this study is automotive commercial advertising. The advertisement used is an advertisement for Yamaha Jupiter MX 2010, an advertisement for Yamaha Jupiter MX 2011, a Yamaha Nmax 2016 ad, an advertisement for Honda Blade 125 Fi 2016, and a Honda Vario Techno 1252015 advertisement. Advertisements are obtained by transcribing audio-visual ads into scripts so that research in analyzing ad text is easier to do. The next step is to change audio-visual and data so that it can be analyzed in this study. Speeches on audiovisual ads are transcribed in text form so that they can be analyzed in more detail. Scenes on audio-visual ads are made screenshots in the form of photos that are inserted in the analysis of this research data. The screenshots are used to show the scenes in the ad containing signs so that data analysis can be used to show which signs are visible in the scene and make it easier to understand the results of the analysis of the data. The secondary data used in this study is derived from the data contained in a literature review that is considered important in assisting the process of data analysis both in terms of reference and from the application of existing theories.

In examining objects that are considered signs in advertisements, the theory that is suitable to be used is the theory of Peirce's triadic structure. Peirce is an American philosopher who created a field of science which he called 'semiotic', which is 'formal doctrine of signs', which is closely related to logic (Peirce, 1958). Peirce argues that the sign is formed through a triangular relationship (triadic relation), namely representamens (which is also called a sign) that is associated with the object being referred to. The relationship produces interpreters (Nöth, 1990; Cobley \& Jansz, 2002). The relationship is also called the triadic structure (Budiman, 1999). Representants are things that can be perceived that function as signs (Nöth, 1990).

1) Representants do not have to be material, (although they are usually interpreted as such), and are referred to by theorists as 'sign vehicle' or 'means of the sign'.

2) Objects are something that Representamens refers to. The object can be an Immediate Object, that is an object as represented by a sign, and a dynamic object (Dynamic Object), which is an object that does not depend on the sign, instead this object stimulates the creation of signs (Cobley \& Jansz, 1990; Nöth, 1990).

3) Interpretation is the effect caused by marking or signs as perceived by our minds.

These three elements must be in order to be called a sign. A sign is a unit of what is represented (Object), how it is represented (Representamens) and how the sign is interpreted (Interpretation).

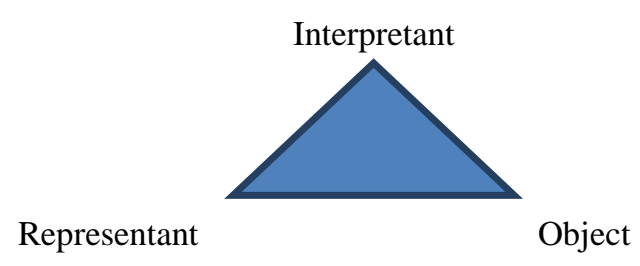

Figure 1. Peirce's Semiotic Triangle

From the Representamen-Object-Interpretant, or R-O-I relationship, a process of meaning and interpretation of signs is called the semiosis process. This process takes place repeatedly. I can function as a new $\mathrm{R}$ that refers to new

Krisnawan, G. N. A., Beratha, N. L. S., \& Laksana, I. K. D. (2019). Commercial automotive advertising: semiotic study. International Journal of Linguistics, Literature and Culture, 5(3), 71-80. https://doi.org/10.21744/ijllc.v5n3.659 
O and new I again, and so continues over and over again to infinity (Hoed, 2002). Cobley (2001), provides an example of a repetitive process of semiosis. Representatives could be smoke suddenly appears around a hilly area in Rocky Mountain National Park in Colorado. An officer saw the sign (smoke). Furthermore, the semiotic object of fire arises in the mind of the officer. Then there is an interpretant which appears that makes the representamen and the object into one and create a concept that something dangerous happens that requires quick action. The officer then asked for help and headed towards the smoke to see the situation. Apparently, there was a fire. The semiotic object then becomes the representamens whose semiotic object becomes the destruction caused by the embers to the surrounding environment. The interpretation that immediately came to mind was that the fire conditions were more severe than he had expected. The dangerous situation, from the initial interpreter, becomes a representamens that makes its semiotic object a camp near a fire. Interpretant that arises is that it involves dangerous things that will happen there. The dangerous situation gave rise to one more representative, namely the people who were camping, which gave rise to a new semiotic object, namely people caught in a fire. The new interpretant that emerged were victims of forest fires in Rocky Mountains National Park. The sign becomes another sign, which causes another sign to appear, and from there it continues to flow. Thus, the sign for Peirce is representative and interpretative, or in other words, representation and interpretation are the hallmarks of the sign (Zoest, 1993).

Peirce divides his semiotic discussion based on three elements, namely in terms of representamen, in terms of relations between representamen and object, and in terms of interpretants. Because what is focused on this research is the object displayed on automotive advertisements and whether the object is included in the sign category, then the discussion used is the relationship of the representamen and its object. Based on the nature of the relationship between representamen and objects, Peirce divides the sign into three, namely Icon, Index, and Symbol.

1) Icon: mode whose representamens is considered very similar, or twins from objects (known by appearance, sound, feeling, taste and smell) are considered the same because they have the qualities of signified: for example portraits/images, cartoons, scale models, metaphors, original sounds on programmed music, sound effects on radio dramas, converted soundtrack films, similar movements, etc.

2) Index: mode whose representamens does not represent an object, but is directly related (physically or cause) to an object. This relationship can be observed or concluded: for example in 'natural signs' (smoke, roar, footprints, sound echoes, non-synthetic odors, and taste), medical symptoms (pain, rash, heartbeat), measuring instruments (thermometers, clock), signal (door knock, telephone ringing), pointing device (pointing using index finger, road sign), recording (a photo, film, video or television show, audio recording sound) personal sign (handwriting, slogan), and others.

Symbols: mode whose representamens (signifier) is not similar to objects (signified) but can change or are very conventional. Therefore this relationship must be approved and studied. Examples of this are in general language (plus special language, alphabet letters, punctuation, words, phrases, and sentences), numbers, morse code, traffic lights, national flags, etc.

\section{Results and Discussions}

After reviewing the advertisements with the theory from Peirce, the following results are obtained.

\section{The icon on Automotive Advertisement}

In this discussion, automotive advertisements from Honda and Yamaha were used. This discussion focuses on the iconic sign in the ad. The first ad is the ad of Honda Vario 125. The first sign of the icon is the woman in the ad. Here is the scene of the woman.

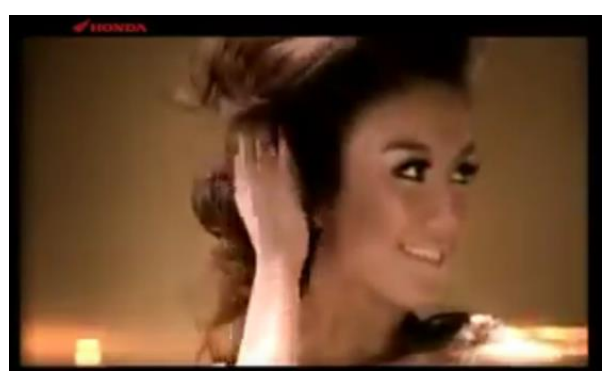

Figure 2. The scene that shows the woman 
Peirce's Triadic Relation

Representamen : Woman in the scene

Object : Woman (Agnes Monica)

Interpretant : The woman in the advertisement is a well-known public figure, singer, and actress in Indonesia, Agnes Monica.

In the scene above there is a woman who appears and starts narrating the contents of the ad. The woman is an actress and singer in Indonesia named Agnes Monica. This type of sign based on the relationship between the representamen and the object is an icon. This is based on observations that the person in the scene (sign) has 100 percent similarity to the object (Agnes Monica).

The meaning of the sign above is the use of public figures that have been known to the public in order to attract the sympathy of the public so they want to listen to advertisements and are interested in the products offered. Since the past, many public figures have been used to star in commercial product advertisements. Besides that, because they (public figures) have names that are well known in the community (work as actors / actresses and singers) so that they can potentially influence people's perceptions of buying products (especially for fans of public figures), also so that they can maintain their existence in the eyes of the public, especially in electronic media.

The second ad is the Yamaha Jupiter MX ad. The second icon is the man in the ad. Here is the scene of the man.

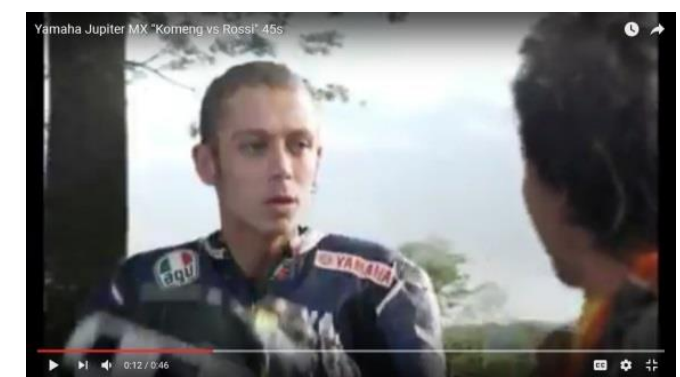

Figure 3. A scene that displays the scene of the man

Peirce's Triadic Relation

Representament : Motorcycle riders.

Object : Motorbike racer named Valentino Rossi.

Interpretant : The motorcyclist is a famous motorbike racer.

The scene above illustrates how when the motorcyclist took off his helmet. Apparently, he is Valentino Rossi. Valentino Rossi is a motorbike racer from Italy. He is one of the most famous motorcycle racers in the world who has many achievements in the highest motorcycle racing event, namely MotoGP racing. This type of sign based on the relationship between the representamen and the object is an icon. This is based on observations that the person in the scene (the sign) bears 100 percent similarity to the object (Valentino Rossi).

The meaning of the sign in the above scene is the use of public figures who are already well-known as motorcycle advertising star. Valentino Rossi is a racing figure who already has a very famous name in the world of motorcycle racing. He was once called the Michael Schumacher of MotoGP because of his outstanding achievements and other racers will be difficult to compete with him. As one of the famous racers who raced for the Yamaha team, it is only natural that Valentino Rossi starred in the advertisement of Yamaha products. Apart from the fact that his name has high selling value, its presence in this advertisement will make public attention focused on this advertisement, especially his fans. The goal of advertisement as an attention object will be achieved and the Yamaha company hopes that with ads that can attract public attention, the sales of their motorcycles will increase

Krisnawan, G. N. A., Beratha, N. L. S., \& Laksana, I. K. D. (2019). Commercial automotive advertising: semiotic study. International Journal of Linguistics, Literature and Culture, 5(3), 71-80. https://doi.org/10.21744/ijllc.v5n3.659 


\section{Index on Automotive Advertisement}

In this discussion, automotive advertisements from Honda and Yamaha were used. This subsection focuses on the index signs contained in the ad. The first ad is the Honda Vario 125. The first index sign is a scene that shows a rotating speedometer needle. Here is the scene.

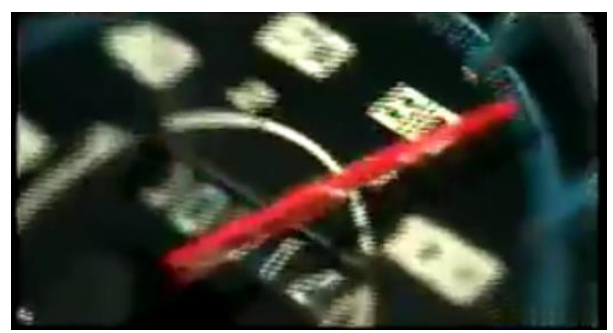

Figure 4. Moving Speedometer Scene

Peirce's Triadic Relation

Representamen : A moving speedometer needle.

Object

: Increased motor speed.

Interpretant

: The speedometer needle moves which indicates the speed of the motor that is increasing rapidly.

In the above scene there is a scene that shows the speedometer needle moving to the right. This indicates that the motorbike is moving faster. This type of sign based on the relationship between representamens and the object is an index. This conclusion is obtained by noting that the needle indicates the speed of the motor that is moving. There is a direct connection between the speedometer needle and the speed of the speeding motorbike. Therefore this type of sign is an index sign.

The meaning of the sign above is a sign representing increasing motor speed. Ads usually have a limited duration, usually between 10 seconds to 1 minute. Due to the limitations of this duration, the things that you want to show in the advertisement must be short and clear to streamline the use of scenes for a limited duration. The use of a speedometer whose needle moves quickly is one form of time efficiency because this scene only takes a second. To show an accelerating motorbike speed, of course, it takes a lot of time to see an increase in motor speed. By using this speedometer, the speeding motorbike scene can be eliminated and replaced with the speedometer scene to represent an increase in motor speed.

The second sign of the index is the motorist's body that is lifted while riding a motorcycle in the Jupiter MX Yamaha ad. Here is the motorist's scene.

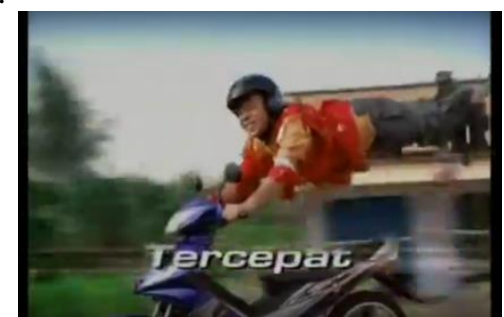

Figure 5. The Scenes of Body Lifting On The Motorcycle

Peirce's Triadic Relation

Representamen : The motorist's body that is lifted.

Object : Motorcycle's speed.

Interpreting : Outstanding motor speed that causes the motorist's body to lift up into the air when riding the motorcycle.

In the above scene, there is a motorist who is speeding. The motorist's body is not on the motorcycle but is lifted into the air due to the very fast motorcycle's speed. This type of sign is based on the relationship between the 
representamen and the object is an index sign. This is based on the observation that the motorist's body that is lifted (a sign) has a direct relationship with the incredible motorcycle's speed (object).

The meaning of the sign above is a sign of interpreting extraordinary motorcycle's speed. The motorcycle's speed causes the motorist's body to lift into the air. The depiction of this scene has an element of hyperbole. This hyperbolic effect is displayed to highlight the main thing that this motorcycle has which is the motorcycle's high speed. This scene is also considered funny because of the effect of hyperbole which exaggerates the reality.

\section{The symbol on Automotive Advertisement}

In this discussion, automotive advertisements from Honda and Yamaha were used. This discussion focuses on the symbol in the advertisement. The first symbol is the white wing logo that appears at the end of the ad on the Honda Vario 125 ad. Here is the scene.

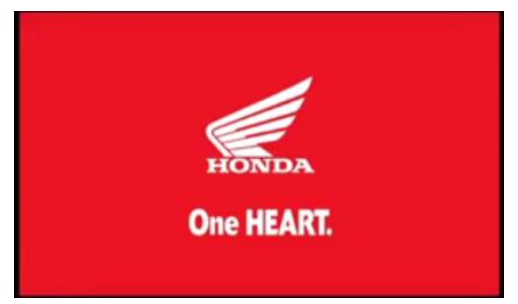

Figure 6. Honda Logo and Slogan

Peirce's Triadic Relation

Representamen : White wing logo with the writing of Honda.

Object : White wing logo.

Interpreting : The white wing logo is the official logo of the Honda Company in the field of motorcycle production.

In the above scene, there is a white wing logo containing the writing of Honda. This logo appears at the end of every Honda automotive product ad. This type of sign based on the relationship between the representamen and the object is a symbol. This is based on the observation that the logo is the Honda Company logo in the field of motorcycle production. This logo represents Honda company and the public knows because of learning it (when looking at an advertisement for Honda motorcycle products, this logo is always there).

The meaning of the sign above is the wing logo representing Honda's company in the field of the motorcycle. This logo was used on the premise of Soichiro Honda, founder of the Honda Company, in 1947. This logo was taken from the concept of Goddess Nike, or "Nenikekamen", the Goddess of Greek mythology. This goddess also appeared in Roman mythology as the Victory Goddess. This goddess is the goddess of the victory symbolizes in the form of a winged woman. Mr. Soichiro then took inspiration from the Victory Goddess and made the wing logo as a symbol of Honda so that Honda is always at the forefront and becomes a winner.

The second sign of the symbol is the tuning fork logo followed by Yamaha's writing on the Yamaha Jupiter MX ad. Here is a scene that displays the logo.

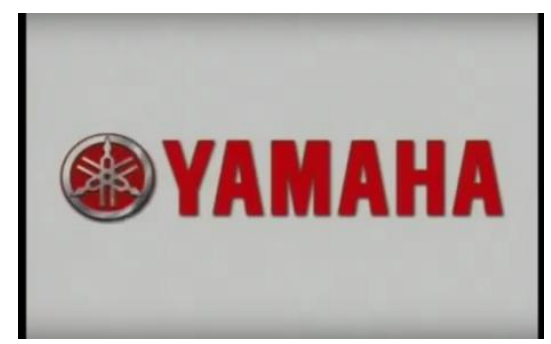

Figure 7. Yamaha logo

Krisnawan, G. N. A., Beratha, N. L. S., \& Laksana, I. K. D. (2019). Commercial automotive advertising: semiotic study. International Journal of Linguistics, Literature and Culture, 5(3), 71-80. https://doi.org/10.21744/ijllc.v5n3.659 


Peirce's Triadic Relation
$\begin{array}{ll}\text { Triadic Relationship Peirce } \\ \text { Representamen } & : \text { The logo of three tuning forks in a circle. } \\ \text { Object } & : \text { Tuning forks logo } \\ \text { Interpretan } & : \text { The tuning forks logo is a symbol of the Yamaha company. }\end{array}$

In the scene above there is a logo of three tuning forks in a circle. This logo appears at the end of every Yamaha automotive product ad. This type of sign based on the relationship between the representamen and the object is a symbol. This is based on the observation that the logo is a Yamaha company logo in the field of motorcycle production. This logo represents the Yamaha company and the public knows because of learning it (when viewing Yamaha motorcycle product advertisements, this logo is always there).

The meaning of the sign above is the logo of three tuning forks in the circle representing the Yamaha company. This logo was used starting in 1927. Previously, the Yamaha company used a Phoenix logo that had the meaning of virtue and grace. This logo was then converted into three tuning forks in the form of a triangle representing three activities carried out by the company, namely manufacturing, marketing, and technology. The symbol of three tuning forks also symbolizes three important elements in music, namely melody, harmony and rhythmic. At that time Yamaha made more musical instruments. Not until 1955 did Yamaha begin to produce their first motorcycle. The logo was changed to three tuning forks in a circle like a logo that we know to date. Since then Yamaha has become one of the largest motorcycle manufacturers in the world and they still produce musical instruments such as drums, pianos, etc.

\section{Conclusion}

The icon of automotive advertising focuses more on who is used as an advertising star. The icon here is a 'face' of an advertisement, so it is very important that this 'face' can attract public attention. Therefore there are many advertisements that use the public figure as the advertising star. In addition to having a face that is known to many audiences, this public figure is also considered to have certain influences, especially to his fans, so that the fans are expected to buy and use the products advertised. This is evidenced in the discussion of the icons in the discussion chapter, which featured two automotive advertisements that used two famous people like their advertising stars.

The index on automotive advertising has a role to shorten the time in a scene or indicate something that is delivered briefly with the right description. Ads have a short duration. If a scene in an ad has a long duration it will be detrimental to the ad maker because with a long duration, the greater the cost incurred to pay for the ad on television. The index functions as a summary of a scene, which can be seen in the two examples discussed. Both of these examples want to show the speed of a very fast motorbike which is the advantage of the two motors. However, when displaying a motorbike scene that explicitly shows the motorbike accelerates faster, it will take a long time to display. Therefore a scene is made which indicates the motorbike is moving rapidly like the two examples above.

The symbol in the discussion above has a function as a company identification, or a trademark of the producer company of the item advertised. Every company must have different logos and names as identifiers and company characteristics so that when consumers search for a product, they can see the company logo as a sign that the product is made by a particular company. In the example above, the Honda and Yamaha company logos are symbols. The logo must be studied by the public so that the public can get to know the logo and which company belongs. Therefore the Yamaha garut logo and Honda wing logo are symbols of the ad.

Icons, indices, and symbols have different roles in an advertisement, but their existence is very much felt. An icon is a real form of what is offered on the ad (the item displayed) and who narrates the ad (the star of the ad), the index as a time saver so that the ad is more efficient, and the symbol as the identifier of the manufacturer of the product advertised. These three factors are interrelated in creating effective and efficient advertisements so that all existing ads have these three factors in the ad. 
Conflict of interest statement and funding sources

The authors declared that they have no competing interest.

Statement of authorship

The authors have a responsibility for the conception and design of the study. The authors have approved the final article.

Acknowledgments

The authors would like to thank the editor team of IJLLC for their valuable time, support, and advice in completing the current article.

Krisnawan, G. N. A., Beratha, N. L. S., \& Laksana, I. K. D. (2019). Commercial automotive advertising: semiotic study. International Journal of Linguistics, Literature and Culture, 5(3), 71-80. https://doi.org/10.21744/ijllc.v5n3.659 


\section{References}

Beasley, R., \& Danesi, M. (2010). Persuasive signs: The semiotics of advertising (Vol. 4). Walter de Gruyter.

Budiman, K., \& Soeratno, S. C. (1999). Kosa Semiotika. LkiS.

Cobley, P. (2001). Semiotics and Linguistics. London and New York: Routledge.

Cobley, P. J. L.(1999). Introducing Semiotics.

Cobley, P., \& Litza, J. (2002). Semiotika for Beginners, Terj Ciptadi Sukono.

Cook, G. (2001). The discourse of advertising. Psychology Press.

Goddard, A. (2005). The Language of Advertising. London: Routledge.

Hoed, B. H. (2002). Strukturalisme, Pragmatik dan Semiotik dalam Kajian Budaya. dalam Indonesia: Tanda yang Retak.

Levy, S. J. (1999). Symbols for sale. Brands, Consumers, Symbols and Research: Sidney J Levy on Marketing, 203212.

Melchenko, L. (2003). Inferences in advertising: A study of Swedish and Russian TV commercials.

Nöth, W. (1995). Handbook of semiotics. Indiana University Press.

Peirce, C. S. CS 1958-1960. Collected papers of Charles Sanders Peirce.

Pinson, C. (1988). Semiotics and marketing communication research. International Journal of Research in Marketing, 3(4).

Zoest, A. V. (1993). Semiotika. Jakarta: Yayasan Sumber Agung. 